\title{
A EDUCAÇÃO DOS SENTIDOS E OS SABERES DA EXPERIÊNCIA: RELAÇÕES E DESAFIOS PARA A FORMAÇÃO DE PROFESSORES DE EDUCAÇÃO FÍSICA
}

\author{
Cristina Rezende Silva, Universidade Federal de São João Del Rei - UFSJ, São João Del \\ Rei, Minas Gerais - Brasil \\ Marise Botti, Universidade Federal de São João Del Rei - UFSJ, São João Del Rei, Minas \\ Gerais - Brasil \\ Ana Carolina Cappelini Rogonni, Universidade Federal de São João Del Rei - UFSJ, São \\ João Del Rei, Minas Gerais - Brasil
}

\section{RESUMO}

O acervo de textos e estudos relacionados à educação dos sentidos com o olhar voltado à Educação Física ainda são escassos, com isso, neste trabalho optamos pela pesquisa de cunho bibliográfico, com o intuito de realizar um levantamento de referenciais sobre a educação dos sentidos e os saberes da experiência. Para enriquecer as discussões, promovemos um diálogo entre os campos: filosófico, biológico e cultural e nos propusemos investigar quais as contribuições da educação dos sentidos para a formação de professores de Educação Física, além de investigar as relações entre os saberes da experiência e a educação do sensível para a formação dos sujeitos. Neste sentido, por meio dos referenciais estudados, podemos concluir que a partir dessa relação sensível entre sujeito e mundo, estabelecida por meio dos sentidos, o professor é capaz de ter um olhar diferenciado frente as suas condutas e sua atuação, pode ser um agente facilitador e instigador do aprendizado dos alunos e assim transformar a sua práxis. Além disso, com relação aos alunos, estes podem se tornar produtores de conhecimentos, construtores e transformadores do seu mundo.

Palavras-Chave: Educação dos sentidos; Experiência; Educação Física; Formação de professores.

\section{THE EDUCATION OF THE SENSES AND THE KNOWLEDGE OF EXPERIENCE: RELATIONSHIPS AND CHALLENGES FOR THE TRAINING OF TEACHERS OF PHYSICAL EDUCATION}

\begin{abstract}
The collection of texts and studies related to the education of the senses with a special looking toward the Physical Education are scarce, therefore, in this paper we chose the bibliographical research, in order to conduct a survey of references on education of the senses and knowledge of experience. To enrich the discussions, we promoted a dialogue between the fields: philosophical, biological, cultural and we proposed to investigate which contributions of education of the senses for the training of teachers of Physical Education, and to investigate the relationships between the knowledge of experience and education of the senses for the formation of the subject. In this perspective, we can conclude that from this sensitive relationship between subject and world, established through the senses, the
\end{abstract}


teacher is able to have a different look besides their conduct and their actions can be a facilitator and instigator of student learning and this way it can transform your practice. Besides that, related to students, they can become producers of knowledge, constructors and transformers of their world.

Key-Words: Education of the senses; Experience; Physical Education; Teacher training.

\section{LA EDUCACIÓN DE LOS SENTIDOS Y EL CONOCIMIENTO DE LA EXPERIENCIA: RELACIONES Y RETOS PARA LA FORMACIÓN DE PROFESORES DE EDUCACIÓN FÍSICA}

\section{RESUMEN}

La colección de textos y estudios relacionados con la educación de los sentidos con la mirada puesta en la educación física son escasos, por lo tanto, en este trabajo hemos elegido la investigación bibliográfica, con el fin de realizar un estudio de referencia sobre la educación de los sentidos y conocimiento de la experiencia. Para enriquecer el debate, se promueve el diálogo entre los campos: filosófico, biológico, cultural e investigamos lo que nos propusimos la contribución de la educación de los sentidos para la formación de profesores de educación física, y para investigar las relaciones entre el conocimiento de la experiencia y la educación sensibles a la formación del sujeto. En este sentido, se puede concluir que a partir de esta delicada relación entre el sujeto y el mundo, establecido a través de los sentidos, el maestro es capaz de tener una perspectiva diferente de su conducta y sus acciones, puede ser un facilitador y promotor de aprendizaje de los estudiantes y así transformar su práctica. Por otra parte, en lo que respecta a los estudiantes, que pueden convertirse en productores de conocimiento, constructores y transformadores de su mundo.

Palabras-Clave: Educación de los sentidos; La experiência; Educación Física; La formación del profesorado. 


\section{INTRODUÇÃO}

O pensamento que constitui a área da Educação Física vem se transformando constantemente, especialmente no que se refere dos anos 80 até os tempos atuais, pois de um pensamento tecnicista tradicional, em que o indivíduo se mostra como um reprodutor de gestos técnicos e executor de movimentos pré-determinados, passa a um pensamento progressista na formação dos sujeitos, em que considera também os aspectos sociais, culturais e históricos da sociedade. Assim, os professores da área perceberam a necessidade de um novo olhar e um novo trato com o movimento e com isso, a partir dos anos 80 vira surgir a perspectiva da "Educação Física como prática social”. ${ }^{1}$

Após este trajeto de grandes mudanças e ações relevantes para a área, vivemos atualmente num processo de consequências e descobertas, pois compreendendo a mesma como prática pedagógica, em que se apropria de diferentes áreas para compor seu objeto de estudo, a Educação Física não educa somente o corpo advindo de uma perspectiva cartesiana, mas sim educa os sujeitos a partir do "se-movimentar". ${ }^{2}$ O sujeito do "se-movimentar" é aquele que o faz por meio de significados, interesses e sentidos, ou seja, o movimento se constitui também por diretrizes históricas, sociais, artísticas e culturais, em que a reflexão e a sensibilidade formam os sujeitos capazes de se permitirem à novas experiências do semovimentar, e as reconhece enquanto algo essencial para a humanização e construção do próprio mundo.

Neste trabalho buscamos compreender como esta educação para os sentidos e significados vêm ocorrendo na formação de professores de Educação Física, embasados num constante diálogo entre alguns campos de sua constituição, sendo estes, o biológico, o filosófico e o cultural. Além disso, articularemos esta educação com os saberes da experiência, pois defendemos que o sujeito que tem intencionalidades com o movimento, sejam elas nas maneiras de aprender e/ou de ensinar, por meio dos sentidos, enquanto ser sensível, também é o sujeito da experiência capaz de se formar e se transformar com as questões que movem a si mesmo e o mundo. Partimos do pressuposto que o professor sensível é o mesmo sujeito que está aberto a novas experiências e que ambos os saberes são capazes de transformar sua realidade e sua práxis. 
Com o intuito de tentar sanar o questionamento: quais seriam as contribuições destes saberes na formação de professores de Educação Física? Propusemos-nos a entender os saberes da experiência e a educação da sensibilidade enquanto conhecimento pedagógico, investigar as relações entre os saberes da experiência e a educação da sensibilidade na formação docente e identificar as contribuições destes saberes para a formação de professores de Educação Física.

\section{PROCEDIMENTOS METODOLÓGICOS}

Com a finalidade de se alcançar os objetivos propostos por este projeto nos atemos a fazer uma pesquisa de cunho bibliográfico, já que se trata de um levantamento de toda a bibliografia já publicada, em forma de livros, revistas, publicações avulsas e imprensa crítica. $^{3}$ Segundo estes autores a finalidade da pesquisa bibliográfica é colocar o pesquisador em contato direto com tudo aquilo que foi escrito sobre determinado assunto. Pode-se dizer que os referenciais bibliográficos, a cerca do tema proposto, são um tanto quanto limitados, principalmente no que se refere à área da Educação Física, por isso será utilizado autores de diferentes áreas, entre elas a Filosofia, a Sociologia, a Antropologia, a Psicologia, entre outras, em que temos a intenção de qualificar as discussões e promover um diálogo acerca dos saberes da experiência e da educação da sensibilidade.

A principal vantagem da pesquisa bibliográfica reside no fato de permitir ao investigador a cobertura de uma gama de fenômenos muito mais ampla do que aquela que poderia pesquisar diretamente. ${ }^{4}$ Sendo assim, o autor citado anteriormente destaca que, "neste tipo de metodologia, pesquisa-se todo e qualquer tipo de documento relacionado ao assunto que se encontra disperso por um espaço, e retira destes, elevados e diferentes tipos de dados". Mas é válido ressaltar que deve ser feito uma análise criteriosa para que não haja erros resultantes de dados coletados.

O mesmo autor também elenca etapas para a elaboração de uma pesquisa bibliográfica, que consiste em: "escolha do tema; levantamento bibliográfico preliminar; formulação do problema; elaboração do plano do assunto; busca das fontes; leitura do material; fichamento; organização lógica do assunto; e redação do texto." A fase de levantamento dos dados possui três etapas: "identificação, localização e compilação, que consiste 
respectivamente em: fazer o levantamento do material; determinar os locais onde estão as informações necessárias e fazer reunião do material. ${ }^{5}$

A busca foi realizada nos portais de periódicos da Capes e nas bibliotecas virtuais da UNICAMP, URGS e USP. Diante de todo este arcabouço de referenciais teóricos metodológicos encontrados sobre estudos bibliográficos, o presente projeto não se propõe a atender todos os referenciais dispostos sobre o tema, mas sim tentará se debruçar sobre os que mais se direcionam aos seguintes descritores: Educação Física, formação de professores, educação dos sentidos e saberes da experiência. Também tem como desafio buscar compreender as contribuições dos saberes da experiência e a educação da sensibilidade, e neste sentido percebemos a necessidade de ampliar nossos horizontes teóricos, indo assim ao encontro com outras áreas do conhecimento.

Assim sendo, consideramos a concretização deste projeto relevante para a área da Educação Física, visto que poucos estudos se referem à temática proposta.

\section{REFLEXÕES A CERCA DA SENSIBILIDADE}

Quando se fala em sensibilidade possivelmente associamos este termo a várias tendências do conhecimento, dentre elas as científicas, as humanas e as filosóficas. Ambas fazem parte de uma rede de conexões em que as relações subjetivas entre o homem e a sociedade os tornam, de diferentes formas, sujeitos sensíveis.

\footnotetext{
De pronto e ao longo da vida aprenderemos sempre com o "mundo vivido", através de nossa sensibilidade e nossa percepção, que permitem nos alimentemos dessas espantosas qualidades do real que nos cerca: sons, cores, sabores, texturas e odores, numa miríade de impressões que o corpo ordena, na construção do sentido primeiro. O mundo, antes de ser tomado como matéria inteligível, surge a nós como objeto sensível. ${ }^{6}$
}

Por tanto, buscamos compreender, neste primeiro tópico de discussão, como ou quais os caminhos percorridos ao longo da existência humana nos tornam sujeitos sensíveis e presente no mundo? $\mathrm{Na}$ tentativa de sanar parcialmente esta questão nos propomos a discutir diálogos da sensibilidade no campo da biologia, da cultura e da filosofia.

Uma relação que pode ser estabelecida entre a sensibilidade e as reflexões no campo biológico é feita por meio dos sentidos. Por definição a sensibilidade é a coleção de capacidades localizadas, especializada na apreensão de determinados aspectos do mundo, 
por meio dos vários órgãos dos sentidos. ${ }^{7}$ Tais sentidos correspondem à visão, audição, olfato, paladar e tato, e estes são subordinados àqueles órgãos que percebem aquilo que se passa, e por meio da sensibilidade esse algo que se passa é interiorizado ao corpo. Há duas formas de interpretar o sentido dos sentidos, uma de forma biológica e outra de cunho filosófico. Na perspectiva biológica, os órgãos do sentido são tratados somente como objeto, simplesmente para desenvolverem aquilo que lhes fora proposto, ou seja, o corpo percebe o que está ao redor, e numa busca pela sobrevivência os utilizam, de maneira que o sentido os sejam úteis.

Para além da ideia proposta pelas reflexões do campo biológico utilitarista dos sentidos, outro caminho para pensá-los seria uma vertente de cunho filosófico, poético e sensível. ${ }^{8} \mathrm{O}$ autor citado anteriormente destaca que, neste caso os sentidos, analogicamente, podem fazer parte de dois tipos de caixas: a caixa de ferramentas e a caixa de brinquedos. Quando ditos parte da caixa de ferramentas eles são utilizados pelos indivíduos como simples forma de sobrevivência, mas quando fazem parte da caixa de brinquedos, eles se transformam em órgãos de fazer amor com o mundo, ou seja, são por meio destes órgãos que os sujeitos encontram a felicidade, o bem-estar e o prazer. Neste momento, mais do que utilizar os órgãos dos sentidos para sobreviver, é importante utilizarmos como um saber, representado aqui como o saber ouvir, saber ver, saber sentir, saber saborear... para dar novos significados à vida, ou seja, é utilizar destes sentidos para descobrir novos caminhos. Sendo que, de forma subjetiva as sensações sentidas por meio dos sentidos pelos sujeitos se estabelecem através de relações com o mundo e constroem outros significados.

Outro campo que dialoga com a sensibilidade é a filosofia, especialmente quando se trata da discussão entre a razão e o seu antagonismo com a sensibilidade. Nesta perspectiva, torna-se necessário que façamos uma reflexão para entender que historicamente a razão e a sensibilidade andaram em sentidos opostos, porém, alguns estudos vão demonstrar que estas podem caminhar juntas para a constituição do homem.

O racional refere-se ao conhecimento logicamente necessário e universalmente válido, considerando que nada de bom ou útil pode vir dos sentidos, ${ }^{9}$ ou seja, considera somente o que é objetivo e verdadeiro como o conhecimento. Alguns estudiosos defendem esta idéia, 
pois, pensavam que agir moralmente é agir racionalmente, e agir racionalmente é filosofar, e filosofar é suprimir o sensível. ${ }^{9}$ É a morte dos sentidos e consequentemente do corpo.

No século XX, alguns fatos foram marcados por esta difusão do pensamento racional:

Guerras, violência, fome, desestabilidade social, desequilíbrio ambiental e o surgimento de novas doenças consolidam-se como características marcantes de um século XX que encontra, na crítica da razão identificada com uma dada racionalidade cientificista e tecnicista, o tom de boa parte das reflexões na área das humanidades. ${ }^{10}$

Diante de tais fatos constatou-se que não somente o pensamento racionalista seria capaz de explicar o sentido do mundo, por isso em contrapartida aquilo que é racional tem-se o sensível. Assim, o sensível é definido como a capacidade de observar os detalhes para intervir em uma situação, da melhor forma possível, também como maneira de criar rupturas com modelos exclusivos da racionalidade congnitivo-instrumental da ciência e da técnica. ${ }^{11}$ Com isto pode-se perceber que a ideia de racionalidade só era possível com a morte do sensível, bem como o sensível só era possível com a morte do racional.

Porém alguns estudiosos estabeleceram analogias entre estes pensamentos, pois, defendem que há uma conciliação entre sensibilidade e razão, onde uma é partícipe da outra, pela via do impulso lúdico e da beleza. ${ }^{12}$ Neta perspectiva entende-se o belo como, um estado em que o homem é como que recriado em todas as suas potencialidades e recupera sua liberdade tanto em face das determinações de sentido, quanto em face das determinações da razão. ${ }^{13}$

Diante disto começa-se a perceber que não somente a sensibilidade e nem só a razão poderia explicar o sentido do mundo ou da existência humana. Em relação a razão entendese que ocorreu um colapso da razão pura, seu esgotamento, na medida em que não serve para viver, em que falhou para enfrentar e interpretar os problemas humanos, e com isso marcou o fim do utopismo e o crepúsculo da modernidade. ${ }^{14}$ Neste sentido, agora a razão e a emoção estão conectadas uma à outra e a supremacia de uma ou outra só poderá resultar na incompletude, na sectarização e no equívoco, ${ }^{12}$ isto implica que da relação existente entre a razão, o sensível e o objeto obtém outro significado, diferentemente do que já foi vivido, mas que se relaciona com as experiências do indivíduo. 
Visto estas reflexões que permeiam o discurso da sensibilidade, neste trabalhamos assumimos que existe um elo entre a sensibilidade e a racionalidade, aqui denominada como razão sensível e também defendida por Michel Maffesoli em seu livro Elogio da Razão Sensível, e estas duas vertentes trabalham juntas para tentar explicar o sentido do mundo. A razão e o sensível, são elementos que irão auxiliar na compreensão dos múltiplos fenômenos sociais e que até então permaneciam incompreendidos ou ignorados pela razão. ${ }^{14} \mathrm{O}$ mundo construído por meio das relações entre os sujeitos e o meio é conduzido a uma experiência sensível que cria a possibilidade de penetração no mundo através do corpo em sua inteireza. ${ }^{15}$ Mas para que seja uma experiência, os sujeitos sensíveis devem estar abertos a elas, para que elas de algum modo possa lhe modificar.

Além dessas reflexões, há outro campo que dialoga com a sensibilidade, o campo da cultura. $\mathrm{O}$ acervo de textos, artigos e livros que tentam entender o significado do termo cultura são diversos, por isso recorremos a alguns desses trabalhos para entender este fenômeno. Percebemos que os significados estão pautados em três dimensões, sendo estas: a dimensão social dos sujeitos, as relações com as crenças e ideais dos povos, além da associação entre trabalho, humanização e linguagem.

Primeiramente existem duas concepções básicas de cultura, a primeira se remete a todos os aspectos de uma realidade social e a segunda refere-se mais especificamente ao conhecimento, às ideias e crenças de um povo. ${ }^{16}$ Diante disto, conseguimos perceber que tudo o que é produzido pela humanidade é cultura, mas, por outro lado toda influência produzida pela realidade social em que os sujeitos estão inseridos, também resulta em distintas culturas.

A cultura também pode ser definida como todo o complexo de conhecimentos e toda habilidade humana empregada socialmente, ${ }^{17}$ isto quer dizer que estes conhecimentos estão para além do plano biológico dos indivíduos, eles fazem parte do processo sócio-histórico construído pelos sujeitos e a totalidade de uma dimensão da sociedade. Esta totalidade a que os autores se referem corresponde a todo o conhecimento construído pela sociedade, por meio das práticas e experiências dos sujeitos. Além disso, ainda há algumas maneiras como esse conhecimento é expresso por uma sociedade, como é o caso de sua "arte, religião, esportes, jogos, tecnologia, ciência e política. ${ }^{16}$ Portanto diante da multiplicidade 
de sentidos sobre cultura, pode-se dizer que toda forma de expressão dos sujeitos que venha a influenciar na sociedade em que este está inserido, todo o conhecimento historicamente construído, além de tudo o que está relacionada com a dimensão da ação social, é cultura. $\mathrm{O}$ fator de mudança social serve não apenas para descrever a realidade $\mathrm{e}$ compreendê-la, mas também para apontar-lhe caminhos e contribuir para sua modificação. ${ }^{16}$

Em mais uma das tentativas de se entender o significado de cultura, o foco se volta para as atividades humanas: do trabalho, da linguagem e da humanização, partindo do pressuposto que estas atividades que fazem com que o homem se diferencie do animal. Primeiramente o trabalho do homem é dirigido por finalidades conscientes, diferentemente do animal que foi programado biologicamente e instintivamente para desenvolver suas habilidades. Em relação a linguagem, os homens possuem um poder de fala capaz de influenciar o mundo que vivem, diferentemente do animal, que sua linguagem visa a adaptação a uma situação concreta, ${ }^{18}$ assim a sua relação com a humanização em conjunto com o trabalho, percebese que por meio do trabalho é que as pessoas se relacionam, que experimentam outras emoções, novas experiências e que interferem sobre o mundo em que vivem. Portanto:

A cultura é o processo pelo qual o homem acumula as experiências que vai sendo capaz de realizar, discerne entre elas, fixa as de efeito favorável e, como resultado da ação exercida, converte em ideias as imagens e lembranças, a princípio colocadas as realidades sensíveis, e depois generalizadas, desse contato inventivo com o mundo natural. ${ }^{18}$

Incumbido a estas reflexões, o indivíduo a se julgar como um ser sensível e humano, expressa esta sensibilidade por meio de suas atitudes e seus significados, ou seja, a medida que este universo se mostra com dados sentidos, por meio das sensibilidades, os sujeitos são passivos e ativos de cultura.

Dois caminhos podem ser levados em consideração nas relações da sensibilidade e das influências culturais aos sujeitos, de um lado os atos barbáricos e do outro as ações humanizadoras. Diante desta sensibilidade que desumaniza, os indivíduos passam a privilegiar alguns em detrimento de outros e isso se evidencia nas relações com o mundo. Por meio destes antagonismos humanos, retratamos que:

A dis-posição do estado sensível nos possibilita o estar-sendo-no-mundocom-os-outros, de modo encarnado e radical, mediante os processos de percepção e de compreensão em que podemos tocar, cheirar, escutar, 
saborear e olhar o mundo, bem como, conjuntamente, pensar, meditar por meio de nossa relação direta e originária com ele. ${ }^{19}$

Com isto, a sensibilidade humanizadora seria o princípio de um processo do homem tornar-se mais humano, da necessidade de ter um novo olhar a tudo o que está ao seu redor e de estarem abertos às particularidades do mundo e por meio do corpo os sujeitos se apropria das atividades culturais que atinge o ser humano na sua totalidade.

\section{DIÁLOGOS ENTRE SENSIBILIDADE E EXPERIÊNCIA}

Para que possamos entender um pouco mais sobre a sensibilidade e seus campos de constituição propomos estabelecer um diálogo entre a sensibilidade e a experiência. Nesta discussão buscamos caminhar por um viés em que o sujeito sensível, de certa forma, também é o sujeito da experiência, ou seja, para vivermos uma experiência é preciso sermos e/ou estarmos sensíveis à ela, pois somente vive experiências aqueles que a sentem e ao mesmo tempo se transformam.

$\mathrm{Na}$ filosofia, experiência significa o conhecimento transmitido pelos sentidos, ${ }^{20}$ ou seja, a apreensão sensível da realidade externa, cuja confirmação ou possibilidade de confirmação pode ser empírica. Dialogando com essa perspectiva a ideia de experiência é sinônimo de conhecimento, mais especificamente, conhecimento que nos é transmitido pelos sentidos. ${ }^{20}$ Com isso, pode-se dizer que só se tornam experiências aquelas que por meio dos sentidos e suas relações com o mundo constroem conhecimentos, sendo assim, os sujeitos da experiência e da sensibilidade, precisam parar para ouvir, para sentir, para refletir... e esta possibilidade:

Requer um gesto de interrupção, um gesto que é quase impossível nos tempos que correm: requer parar para pensar, parar para olhar, parar para escutar, pensar mais devagar, olhar mais devagar, e escutar mais devagar; parar para sentir, sentir mais devagar, demorar-se nos detalhes, suspender a opinião, suspender o juízo, suspender a vontade, suspender o automatismo da ação, cultivar a atenção e a delicadeza, abrir os olhos e os ouvidos, falar sobre o que nos acontece, aprender a lentidão, escutar aos outros, cultivar a arte do encontro, calar muito, ter paciência e dar-se tempo e espaço. $^{21}$

Diante das relações estabelecidas entre os sujeitos e o mundo é que podemos perceber as experiências vividas ou não por eles, por isso, dialogamos com a ideia de que a experiência 
como o que nos passa, o que nos acontece e o que nos toca e não o que se passa, não o que acontece, ou o que toca. ${ }^{21}$ Corroborando com a idéia de que:

Fazer uma experiência com algo significa que algo nos acontece, nos alcança; que se apodera de nós, que nos tomba e nos transforma. Quando falamos em "fazer" uma experiência, isso não significa precisamente que nós a façamos acontecer, "fazer" significa aqui: sofrer, padecer, tomar o que nos alcança receptivamente, aceitar, à medida que nos submetemos a algo [...]. Podemos ser assim transformados por tais experiências, de um dia para o outro ou no transcurso do tempo. ${ }^{21}$

Além disso, cada sujeito vive sua experiência de uma maneira, esta traz sentidos e significados distintos para cada um, isto quer dizer que a experiência se traduz como tudo aquilo que acontece e afeta de algum modo, produz alguns afetos, inscreve algumas marcas, deixa alguns vestígios, alguns efeitos. ${ }^{21}$ As relações estabelecidas entre o meio com o mundo para que os sujeitos possam passar por experiências é definida como a relação com o saber. ${ }^{22} \mathrm{O}$ saber é um conhecimento produzido pelo sujeito confrontado a outros sujeitos e construído em uma história coletiva de pluralidades das relações entre homem e mundo. Vivo e me construo na sociedade, mas nela vivo coisas que nenhum ser humano, por mais próximo que seja de mim, vive exatamente da mesma maneira. ${ }^{22}$

Sendo assim, os saberes da experiência são saberes dotados de singularidades, particularidades, além de estarem ligados à subjetividade de cada sujeito. Isto implica que, cada ser humano irá perceber as experiências de alguma forma, distintas ou não. Na visão do filósofo alemão Gadamer experiência não é o que acontece, mas o que nos acontece, duas pessoas, ainda que enfrentem o mesmo acontecimento, não sofrem a mesma experiência. ${ }^{23}$ Assim como para Aristóteles ${ }^{1}$ a experiência é apreensão do singular. ${ }^{20}$

Como neste trabalho, partimos da ideia de que o sujeito da experiência é também o sujeito sensível, percebemos que a sensibilidade não é algo que pode se tornar modelo, esta não se separa do indivíduo que a vive, ela só tem sentido no modo pelo qual configura uma personalidade, um caráter, uma sensibilidade ou, enfim, uma forma humana singular que é, por sua vez, ética (um modo de se conduzir) e uma estética (um estilo). ${ }^{21}$ Além disso, cada um tem sensações próprias, diferentes e até contraditórias diante dos mesmos objetos,

\footnotetext{
${ }^{1}$ ARISTÓTELES. Ética à Nicômaco. Trad. Mário Gama Kury. 4ªed. Brasília: UNB, 2001. 
portanto a sensibilidade não é algo que se pode educar, mas sim os sentidos. ${ }^{24} \mathrm{~A}$ afirmação deste autor confronta com a ideia de Nicola Abbagnano ${ }^{2}$ quando diz que o sensível é “aquilo que pode ser percebido pelos sentidos. ${ }^{6}$ Nesta acepção, 'o sensível' é o objeto próprio do conhecimento sensível. Neste trabalho caminhos por essa linha de que, os órgãos do sentido são um meio para a sensibilidade, a educação dos sentidos é o fim para o corpo sensível.

\section{FORMAÇÃO DE PROFESSORES}

No que envolve a formação de professores, ainda são poucas as relações e as discussões estabelecidas que envolvem a educação dos sentidos. Percebe-se que as Universidades estão cada vez menos se preocupando com os aspectos que norteiam a sensibilidade e seus campos de constituição. Algumas pesquisas retratam a dificuldade dos professores em se trabalhar o corpo sensível em sala de aula. Uma das hipóteses de tais dificuldades encontradas, em que esses saberes são difíceis de serem operacionalizados, pode ser por que a corporeidade e a sensibilidade ainda não são instâncias muito valorizadas pela Universidade, faltam discussões e vivências desses aspectos nas aulas e na própria formação do profissional da educação. ${ }^{25}$ Entendemos que essa hipótese é construída sob o reflexo e consequência do pensamento científico e racional do séc. XIX, em que este se sustentava essencialmente pela razão, negando assim uma busca do conhecimento por meio da sensibilidade. Essas consequências refletem até hoje no trato dualista dado ao corpo, em que não só há uma separação de corpo e mente, mas também uma sobreposição valorativa da mente sobre o corpo.

Diante deste pensamento cartesiano, a preocupação envolve o trato com os sentidos, diretamente ligados com a relação que os sujeitos estabelecem entre o que está externamente aos sujeitos e a forma com que elas são interiorizadas por meio do corpo sensível, para isso a função dos educadores é ensinar o aluno a ver, principalmente, mas também a sentir, a ouvir, a escutar e a falar. ${ }^{8}$ Aprendizes de tais ensinamentos, os alunos são capazes de perceberem as experiências, de defini-las e de transformá-las como algo que os constituem. Como consequencia desta visão dualista, defendida por descartes, em que ocorre uma divisão entre o corpo e a mente, percebe-se que há uma supervalorização

\footnotetext{
${ }^{2}$ ABBagnano, Nicola. Dicionário de filosofia. São Paulo: Mestre Jou, 1970.

Conexões: revista da Faculdade de Educação Física da UNICAMP, Campinas, v. 12, n. 2, p. 114-131, abr./jun. 2014. ISSN: 1983-9030
} 
do intelecto pela sociedade, e pela escola, fazendo com que os sentidos se tornem mecânicos e a criança reduza sua capacidade sensitiva. ${ }^{6}$

O professor formado para uma educação do sensível está aberto a essas novas experiências e segundo uma pesquisa que buscava elucidar e analisar um dos aspectos dos saberes docentes, entre eles os saberes da experiência, entende que este é um possível caminho para o alcance da autoria da sua prática pedagógica, autônoma, crítica e consciente. ${ }^{26}$ Entende-se assim que por meio das experiências os professores se tornam sujeitos e transformadores de suas práticas, produtores de saberes e conhecimentos, além de ser um agente facilitador e instigador do processo do ensino e da aprendizagem dos alunos. Com isso, possibilita superar a posição "ingênua" de adaptação ao mundo para a posição crítica de inserção no mundo. ${ }^{27}$ Um exemplo disso, é se o professor tem sensibilidade para ouvir a criança e respeitar a sua individualidade, ele pratica a escuta sensível e é capaz de planejar suas ações de acordo com as necessidades apresentadas pelos alunos. ${ }^{28}$

O despertar dos sentidos dos alunos depende também de que o professor tenha os seus despertos, pois não acredito que um professor que esteja "dormindo" possa "acordar" seus alunos. Acredito que é através do experimento que o professor pode atingir um despertar dos sentidos. ${ }^{9}$

É válido ressaltar o papel e o diálogo constante entre professores e escola nas questões que permeiam a educação dos sentidos. Com isso, a escola passa a se ausentar de seu papel, pois, não explora a educação dos sentidos e os sentimentos, mostrando que os alunos ao saírem da escola têm olhos, ouvidos... perfeitos, mas não parece tê-los desenvolvidos por não saberem enxergar, ouvir e sentir cheiros. ${ }^{29}$ Diante disto, nota-se que o sistema educacional ainda separa o corpo e o intelecto dos sujeitos, bem como a ideia de descartes. Em contraposição a essa ideia, neste trabalho entendemos que estas instâncias não podem ser separadas, elas são uma unidade que constitui o todo dos sujeitos.

Diante dessas reflexões apontadas anteriormente, percebemos que especialmente na formação de professores de Educação Física, que tem como objeto de estudo a cultura de movimento $^{2}$, ainda se constitui de parâmetros especificamente cientificistas e tradicionais, o que traz enormes conseqüências ao trato com o corpo. Relacionado a este trato com o corpo, dar novo sentido aos órgãos dos sentidos é uma questão difícil, pois:

Algumas questões como: vergonha do próprio corpo, bloqueios a certos movimentos, e o próprio toque parece ser algo proibido, pecaminoso até. 
Só em alguns momentos demarcados e "permitidos" é possível pô-los em ação, onde, agora sim, pode-se dar asas à imaginação [...] precisamos voltar a sentir as texturas da vida. ${ }^{9}$

Para sistematizar esse ensino e educar os sentidos, foi desenvolvido um trabalho denominado Estudo dos sentidos no ensino da Educação Física ${ }^{30}$ que propôs no ensino na educação básica infantil o tema aprendizagem sensorial, trabalhando a partir de aulas práticas, centradas nas vivências sensoriais e como resultados obtiveram que:

As atividades produziram uma melhor concentração das crianças, elas estão mais perceptivas ao espaço educativo, e com mais facilidade de interagir uns com os outros, devido o desenvolvimento de atividades que usavam o diálogo como vínculo das relações sociais e da intimidade social, e também a ampliação sensorial. Possibilitando as crianças uma abertura ao mundo dos sentidos e desenvolvendo a capacidade sensitiva. ${ }^{30}$

Sem dúvida, é uma tarefa difícil, devido a realidade do sistema educacional, porém, neste trabalho evidencia-se que é possível trabalhar buscando educar os sentidos, aumentando as relações estabelecidas pelos sujeitos com o mundo e dar um novo sentido a elas, por meio de suas experiências sensoriais e suas formas de interpretação da realidade. Sendo assim, faz-se necessário um trabalho que proporcione às crianças experiências que renovem e fortaleçam a consciência de si em relação ao mundo, pois é através dos sentidos que relacionamos com nós mesmos, ao mesmo tempo em que estabelecemos contato com o mundo. $^{30}$

\section{CONSIDERAÇÕES FINAIS}

A sensibilidade do indivíduo constitui, assim, o ponto de partida (e talvez, até o de chegada) para nossas ações educacionais com vistas à construção de uma sociedade mais justa e fraterna, que coloque a instrumentalidade da ciência e da tecnologia como meio e não como fim em si mesmas. ${ }^{31}$

Entender a educação dos sentidos está diretamente ligado em compreender e se envolver no universo dos sujeitos e as relações que eles estabelecem com o meio em que estão inseridos. Esta relação sensível com o mundo acontece por meio dos sentidos. Os sentidos são órgão de fazer amor com o mundo, ${ }^{8}$ eles são responsáveis pela experiência sensível dos sujeitos e por dar um novo sentido ao que está diante dos mesmos.

Neste trabalho, tentamos entender a educação dos sentidos a partir de outros conhecimentos e dialogando com outras áreas. Cada campo de constituição entende a 
educação dos sentidos de uma forma, nesta perspectiva buscamos três campos distintos que nos deram subsídios para compreender a sensibilidade, entre eles o campo biológico, em que os autores investigados entendem que os sentidos são utilizados somente para a sobrevivência, como um objeto. Já no campo da filosofia a sensibilidade se relaciona aos novos sentidos e significados estabelecidos pelos sujeitos diante do mundo, além disso, há também um diálogo divergente entre a razão e a sensibilidade, que a priori foram entendidas como antagônicas, mas que surgem novas instâncias que pensam e defendem a união destes elementos para que se possa entender que a educação humanizadora e sensível dos sujeitos acontecem pela fusão razão-sensível. Por fim, discutimos a sensibilidade no campo da cultura, e percebemos que é por meio dos sentidos que os sujeitos se expressam e influenciam a sociedade.

Envolvemo-nos também em questões que permeiam a sensibilidade e seus campos de constituição fazendo um paralelo com a experiência, para tentar entender como esses saberes podem influenciar na formação de professores, mais especificamente, na formação de professores de Educação Física. Diante disso, percebemos que, como consequência das ideias de Descartes de separação de corpo e mente, o sistema educacional, desde a Escola de Ensino Básico até as Universidades, não trabalham com a educação dos sentidos e com isso, os alunos não são preparados de forma transformadora e humanizadora para ouvir, sentir, cheirar, ver e saborear o mundo em que vive, o outro e a si próprios para além do que está diante deles. Sendo assim, as possibilidades do professor de ter uma formação para o sensível estão envolvidas com novas experiências, como por exemplo, com as artes e a música, tendo como objetivo se educar e avançar na formação dos sujeitos para o mundo.

\footnotetext{
Uma educação que vise ampliar as potencialidades e dimensões do ser humano precisa dedicar-se aos processos sensíveis que se dão em nós. $\mathrm{O}$ corpo enquanto detentor destes processos sensíveis, que permite/provoca o sentimento de estar no mundo, consiste no saber primeiro de que nos valemos para estabelecer relações com as pessoas, com o mundo, com os outros saberes. ${ }^{12}$
}

O importante, é que neste processo de auto-formação e de formação é que o resultado possa tornar sujeitos mais sensíveis, autônomos, críticos, éticos e mais humanos, produtores e construtores de um saber sensível. 
Com o fim deste estudo, abrimos um leque de possibilidades para pensar em educar os sentidos, norteando um caminho sensível para novas experiências e novos saberes. Ao mesmo tempo, não nos esgotamos somente neste trabalho e muito menos estamos sugerindo tal propósito aos demais pesquisadores, isto porque apontamos ainda a possibilidade de operacionalizar a educação dos sentidos na realidade escolar, mais especificamente na Educação Física, baseando-se nas experiências corporais dos alunos e nas relações sensíveis estabelecidas por eles com o mundo.

\section{REFERÊNCIAS}

1 OLIVEIRA, V. M. Consenso e conflitos da educação física brasileira. Campinas: Papirus, 1994.

2 KUNZ, E. Transformação didático-pedagógica do esporte. Ijui: Ed. da UNIJUÍ, 1994.

${ }^{3}$ MARCONI, M. A.; LAKATOS, E. M. Metodologia do trabalho científico. 5. ed. rev. ampl. São Paulo: Atlas, 2001.

${ }^{4}$ GIL, A. C. Como elaborar projetos de pesquisa. 4. ed. São Paulo: Atlas, 2002.

${ }^{5}$ RAUEN, F. J. Roteiro de pesquisa. Rio do Sul: Nova Era, 2006.

${ }^{6}$ DUARTE JR. J. F. O sentido dos sentidos: a educação (do) sensível. 200. Tese (Doutorado) - Faculdade de Educação, Universidade Estadual de Campinas, Campinas, São Paulo, 2000.

${ }^{7}$ VALVERDE, M. Corpo e sensibilidade: os sentidos do corpo. In: VALVERDE, M. Estética da comunicação. Salvador: Quarteto, 2007. p. 249-262.

${ }^{8}$ ALVES, R. Educação dos sentidos e mais. Campinas: Verus, 2005

${ }^{9}$ SAlGADO, L. C. D. Educação Física e sensibilidade: diálogos com um método sensível. 2003. Dissertação (Mestrado em Educação Física) Faculdade de Educação Física, Universidade Estadual de Campinas, Campinas, 2003.

Conexões: revista da Faculdade de Educação Física da UNICAMP, Campinas, v. 12, n. 2, p. 114-131, abr./jun. 2014. 
${ }^{10}$ CHINEllato, D. D. Por uma razão estética: um ele entre o inteligível e o sensível. 2007. Dissertação (Mestrado) - Instituto de Artes, Universidade Estadual de Campinas, Campinas, 2007.

${ }^{11}$ TERRA, M. G. et al. Sensibilidade nas relações e interações entre ensinar e aprender a ser e fazer enfermeiro. Revista Latino-Americana, Ribeirão Preto, n.18, v. 2, p. 64-71, mar/abr. 2010.

${ }^{12}$ FIAMONCINI, L. Dança na escola: a busca de elementos na arte e na estética. 2003. Dissertação (Mestrado) - Universidade Federal de Santa Catarina, Florianópolis, 2003.

${ }^{13}$ SANTIN, S. Educação Física: ética, estética, saúde. Porto Alegre: Edições EST, 1995.

${ }^{14}$ HARTKE, S. H. Relação teórico-filosófico entre a razão e a sensibilidade para a produção do direito na pós-graduação. 2007. Dissertação (Mestrado em Ciência Jurídica) - Universidade do Vale do Itajaí, Itajaí, 2007.

${ }^{15}$ FERNANDES, C. S. Entre a razão instrumental e a razão sensível: o conceito de potencialidade estético-comunicativa como proposta teórico compreensiva das sociabilidades ou comunicabilidades contemporânea. In: CONGRESSO LUSOCOM: COMUNICAÇÃO, ESPAÇO GLOBAL E LUSOFONIA, 8., 2009, Lisboa. Anais... Lisboa: Universidade Lusófona de Humanidades e Tecnologias, 2009.

${ }^{16}$ SANTOS, J. L. O que é cultura. São Paulo: Brasiliense, 2006. (Coleção Primeiros Passos; 110).

${ }^{17}$ SILVA, K. V.; SILVA, M. H. Dicionário de conceitos históricos. São Paulo: Contexto, 2006.

${ }^{18}$ ARANHA, M. L. A.; MARTINS, M. H. P. Filosofando: introdução à filosofia. São Paulo: Moderna, 1986. 
${ }^{19}$ ARAÚJO, M. A. L. Os sentidos da sensibilidade e sua fruição no fenômeno do educar. Educação em Revista, Belo Horizonte, v. 25, n. 2, p. 199-222, ago. 2009.

${ }^{20}$ MEINERZ, A. Concepção de experiência em Walter Benjamin. 2008. Dissertação (Mestrado em Filosofia e Ciências Humanas) - Instituto de Filosofia e Ciências Humanas, Universidade Federal do Rio Grande do Sul, Rio Grande do Sul, 2008.

${ }^{21}$ BONDÍA, J. L. Notas sobre a experiência e o saber de experiência. Revista Brasileira de Educação, Campinas, n. 19, p. 20 - 28, jan./abr. 2002.

${ }^{22}$ CHARLOT, B. Da relação com o saber: elementos para uma nova teoria. Porto Alegre: ATMED, 2000.

${ }^{23}$ BONDÍA, J. L. Literatura, experiência e formação. Entrevista concedida a Alfredo Veiga Neto. In: COSTA, M. V. (Org.). Caminhos investigativos III: novos olhares na pesquisa em Educação. Porto Alegre: Mediação, 2008.

${ }^{24}$ SANTIN, S. Humanização e sensibilidade: um novo olhar na enfermagem: perspectivas para novo milênio. 1998. Disponível em: http://www.labomidia.ufsc.br/Santin/Saude/4_Humanizacao_e_sensibilidade.pdf. Acesso em: 20 mar. 2012.

${ }^{25}$ PEREIRA, L. H. P.; BONFIM, P. V. A corporeidade e o sensível na formação e atuação docente do pedagogo. Contexto e Educação, Ijuí, n. 75, p. 45-68, jan./jun. 2006.

${ }^{26}$ ALMEIDA, G. C. F. Os saberes da experiência como princípio da autoria docente. CONGRESSO GOIANO DE CIÊNCIAS DO ESPORTE, 6., 2009, Goiânia. Anais... Goiânia: CBCE, 2009

${ }^{27}$ CANELLA, D.; MATELA, R. C. P. Saberes da experiência na construção de nossos saberes escolares: um diálogo constituinte? Revista Eletrônica do Grupo Aleph, UFF, ano 2, n. 9, fev./mar. 2006. 
${ }^{28}$ NUNES, L. de S. Escuta sensível do professor: uma dimensão da qualidade da educação infantil. 2009. Dissertação (Mestrado em Educação) - Faculdade de Educação, Universidade de Brasília, Brasília - DF, 2009.

${ }^{29}$ ALVES, R. O corpo e as palavras. In: BRUHNS, H. (Org.) Conversando sobre o corpo. Campinas: Papirus, 1994.

${ }^{30}$ BEZERRA, A. S.; SOUSA R. C.; SILVA P. N. G. Estudos dos sentidos no ensino da Educação Física. In: ENCONTRO DE INICIAÇÃO À DOCÊNCIA, 11., 2008, Paraiba. Anais... Paraíba: Universidade Federal da Paraiba, 2008.

${ }^{31}$ DUARTE JR. J. F. Fundamentos Estéticos da Educação. Campinas: Papirus, 1988. 